\title{
The Influence of Youth and Parent Reports of Parental Knowledge and Monitoring and Reporting Discrepancy on High-Risk Youth Offending ${ }^{1}$
}

\author{
Leana A. Bouffard, Iowa State University \\ Gaylene S. Armstrong, University of Nebraska Omaha
}

\begin{abstract}
Research Summary: Positive parenting practices are known to be related to lower levels of youth offending. Questions remain as to the overlap between youth and parent perceptions of parenting practices, and the relationship of perception discrepancies with youth offending. This study examines the concordance of parenting behaviors reports, the relationship between parent and youth perceptions of parenting measures with youth offending, and whether discordant youth and parent reports are related to heterogeneity in youth offending. Methods: Survey data from 818 high risk U.S. youth averaging 16 years old who participated in the Pathways to Desistance study and his or her parent form the basis of this analysis. Results and Conclusions: Results demonstrate youth and parent reports of parental knowledge and parental monitoring are correlated, yet independent predictors of youth offending variety scores. Youth and parent reports about parenting measures demonstrate youth offending is highest when youth perceive parents as uninvolved, and lowest when youth estimates of parental knowledge and monitoring are higher than parent estimates. Parenting matters for high-risk youth, especially in reducing the likelihood of property offending. Using multiple perspectives to assess parenting practices is important in studying these dyadic relationships.
\end{abstract}

Keywords: offending, high risk youth, parental monitoring

\section{Introduction}

Research examining the influence of parenting on youth offending builds upon the assumption that positive parenting practices facilitate a child's healthy psychosocial development and reduce their negative externalizing behaviors including offending (Johnson et al. 2011; Perez-Gramaje et al., 2020). Historically research in this area focused on the parent-youth relationship, family dynamics, and varying strategies used to control youth behavior as central components to positive development and prevention of delinquent behavior (see for example Gottfredson \& Hirschi, 1990; Hirschi, 1968, 1969). More recent research has sought to define parenting practices and strategies that are related to delinquency prevention.

\footnotetext{
${ }^{1}$ This is the author's post print (CC-BY-NC-ND 4.0). Final version publishing in Journal of Adolescence (Accepted 10/31/21).Corresponding author: GArmstrong@unomaha.edu
} 
These studies have examined the relative influence of parental monitoring that structures or limits opportunities and provides discipline for rule breaking (Augenstein et al., 2016), and the importance of creating affective bonds in which youth value the normative expectations of their parents and adjust their behavior accordingly (Hoeve et al., 2012). Studies consistently find that parenting matters for the reduction and prevention of delinquent behavior but often fails to consider aspects of the dyadic nature of a parenting relationship.

In refining our knowledge and understanding of different parenting styles, oftentimes researchers only consider the singular perspective of the parent. Through this lens, parenting style is understood to be the practices or strategies that parents, or parental figures employ in child rearing, which may include expression of attitudes toward a child's responsibilities and specific parenting practices (Bornstein \& Zlotnik, 2008). For example, studies have addressed the validity of indicators that ask youth how much their parents know about their behavior or how closely the youth perceives that they are monitored by their parents, which are common approaches used in the literature on parenting (e.g., Augenstein et al., 2016). Questions arise as to the relationship of these dimensions with delinquency outcomes, as well as whether youth perceptions of parenting are valid as a stand-alone measure of parenting practices (e.g., Walters, 2019).

The current study advances the existing literature by examining the extent to which parent and youth reports of parenting behaviors are congruent, whether parent or youth reported measures of parenting have more influence on youth offending, and how discrepancies between youth and parent reports are related to offending. Importantly, this study strengthens the knowledge in this area of the literature because of two key features. First, we examine a high-risk population of incarcerated youth to ensure a sufficiently high likelihood of delinquent behavior exists in comparison to non-system involved youth (Bechtold et al., 2014; Snyder \& Sickmund, 2006). Second, self-reported offending by youth is utilized as the outcome measure, which researchers suggest is a more valid measure of offending than official records (Brame et al., 2012; Farrington et al., 2003; Maxfield et al., 2000). Researchers suggest much youth misconduct goes undetected by law enforcement officials. Moreover, the complexities of the parentyouth relationship are recognized as dyadic, and behaviors are not viewed through a singular lens of parent to youth influence, but with recognition that reciprocal effects should be recognized in longer term research efforts.

\section{PARENTING AND YOUTH OFFENDING}

A parenting style characterized by a warm, firm relationship between the adult and child is more likely to lead to positive and prosocial developmental outcomes. Researchers find youth exposed to an "authoritative" style of parenting, which includes high levels of behavioral regulation and high levels of

parental support, are "more psychologically competent, more successful in school and less prone to 
internalizing or externalizing problems" (Steinberg et al., 2006, pp. 48; see also Steinberg, 2001; Steinberg et al., 1992). Studies examining community samples of youth find that authoritative parenting significantly reduces the likelihood of negative youth outcomes. Based on results from a longitudinal study of 1,049 youth, Luyckx and colleagues (2011) characterize authoritative parenting as optimal for long-term youth development, with a decreased likelihood of cigarette and alcohol use and less engagement in anti-social behavior.

Extending this linkage between parenting style and youth behavior beyond a community sample, Steinberg and colleagues (2006) studied a sample of 1,355 delinquent youth, finding that offenders from authoritative households on average have higher empathy and temperance, achieve higher grades in school, report a stronger bond to school and their teachers, and report less anxiety and externalizing problem behaviors as compared to youth exposed to harsh, lax, or inconsistent parenting styles. The positive impact of authoritative parenting on youth outcomes is very robust among some youth, so much so that its effects mediate or transcend individual level risk factors such as family ethnicity, peer relationships, and genetic predisposition (Bountress et al., 2017; Chung \& Steinberg, 2016; Simons et al., 2005; White et al., 2016).

\section{Dimensions of Parenting related to Youth Behavior}

Studies have moved beyond typological assessment of parenting styles (i.e., authoritative, authoritarian, indulgent, or uninvolved) to examine the relative influence of varying parenting dimensions of behavioral regulation and support (Maccoby \& Martin, 1983) on delinquency. As noted earlier, oftentimes researchers have viewed these dimensions in a unidirectional relationship with parenting influencing the youth without other considerations. For example, behavioral regulation is typically comprised of parental monitoring and parental knowledge of youth behavior. Parental monitoring is considered as the extent of a parent's level of control or active supervision including boundary or rule setting (Dishion \& McMahon, 1998). Parental knowledge is considered as the extent of a parent's awareness of the youth's location and the activities in which they are engaged (Vieno et al., 2009). Studies often combine these elements of parental behavioral regulation of youth, however, Augenstein and colleagues (2016) argue these are distinct constructs but interrelated. For example, Vieno and colleagues (2009) examined 840 mother-youth dyads finding in dyads reporting higher levels of maternal monitoring, higher levels of maternal knowledge of youth activities also existed. Augenstein et al. (2016) comment that when parents know more about their child's whereabouts and activities, they may be less inclined to initiate stricter rule-setting (i.e., monitoring). For this reason, understanding parental knowledge and monitoring behaviors distinctly is important in understanding the parental role in delinquency prevention. 
In focusing on dimensions of parenting style such as behavioral regulation, the assumption is higher levels of parental knowledge and monitoring reduces the likelihood of negative youth outcomes. Findings from Vieno and colleagues (2009) support this assumption. They find greater maternal knowledge of youth behavior is correlated with fewer self-reported incidents of antisocial behavior. Others argue parental knowledge and, in turn parental monitoring may be a protective factor against the development of child maladjustment including delinquent behavior (Ohannessian et al., 2016).

Often overlooked is the reciprocal influence of the parent-youth dyad, which becomes clearer when researchers consider indirect aspects of behavioral regulation. For example, behavioral regulation may occur indirectly through parental solicitation of information from the youth to enhance their parental knowledge. Successful transmission of knowledge from youth to parent assumes a youth is willing to disclose information to the parent (de los Reyes et al., 2010). Disclosure requires an interactive or transactional process of positive communication in the parent-youth dyad (Lippold et al., 2011) whose success will vary by the level of trust and quality of the dyadic relationship, or the affective bond between parent and child. When successful, this transactional communication process supports both parental knowledge and impact subsequent parental monitoring (Lippold et al., 2011). When unsuccessful, the lack of youth to parent communication may contribute to a parent's inability to engaged in effective behavioral regulation or interrupt delinquent pathways.

In addition to behavioral regulation, parental support is another robust dimension connected to both parental knowledge/monitoring and delinquency. Common indicators of parental support are expressions of warmth, empathy, and perspective-taking, combined with avoidance of negative parenting behaviors such as the expression of hostility toward the youth (Davidov \& Grusec, 2006; Luyckx et al., 2016). Williams and Steinberg (2011) emphasize the importance of accounting for multiple dimensions of parenting including behavioral regulation and parental support. They hypothesize these different dimensions may be related to distinct youth outcomes including socioemotional development and misbehavior. Applying parallel growth curve models to data from the Pathways to Desistance study to test their theory, Williams and Steinberg (2011) examine the relative influence of the parental support and behavioral regulation dimensions on offending, finding that both contribute to delinquency patterns over the three-year period examined. As anticipated, higher levels of parental warmth led to less delinquency, and higher levels of parental hostility led to more delinquency. Similarly, higher levels of parental monitoring led to declines in delinquency over time. Interestingly, although the influence of parental warmth remained consistent, the relative influence of parental hostility and monitoring declines over time. Williams and Steinberg (2011) are careful to note that "although positive parenting clearly did not prevent the adolescents in this sample from becoming delinquent, it was nonetheless associated with desistance from antisocial activity" (p. 643). 


\section{Differences in Parenting by Reporter}

While initial studies demonstrate the importance of measuring parenting dimensions, it remains unclear whether the underlying mechanism influencing offending is the youth's subjective perception or concrete parenting behaviors. Lippold and colleagues (2011) suggest youth and parents may have different perceptions during the transactional process of information sharing. Youth perceptions of how much parents know about and attempt to control their activities may subsequently impact their delinquent involvement. Moreover, researchers suggest children are more strongly influenced by their own perceptions of parental behavior rather than what parents may be doing or think they are doing (Demo et al., 1987). Clarification on the relative importance of youth perceptions as compared to parental perceptions of parenting as an influence on youth offending is needed.

Early studies examining the influence of parenting styles on youth outcomes relied heavily on the perspective of parents and/or other observers such as teachers (Gaylord et al., 2003). Criticism followed suggesting researcher reliance on single reporter perceptions, especially parents, presents difficulty in determining the validity. A better approach is to examine the perceptions of the parent youth dyad. Congruent reporting between parent and youth may be reflective of strong attachment that facilitates communication and information sharing resulting in higher levels of parental knowledge perceived by both (Lippold et al., 2011). It is equally possible that the parent can either over or under report a behavior, with each difference having unique implications. Discordant reporting between parent and child may be a normative developmental process that occurs with aging as youth become increasingly independent of parents (Augenstein et al., 2016). Alternatively, large disparities in parent and child perceptions may reflect underlying conflict in that relationship (Ksinan \& Vaszonyi, 2016). De Los Reyes and colleagues (2010) suggest if a parent over-reports youth behavior, it may indicate a lack of information about the child's activities (i.e., low parental knowledge). Low parental knowledge can also result in a positive illusion bias - a commonality among many parents (Wenger \& Fowler, 2008), leading a parent to also underestimate the potential for the child's involvement in delinquency. In contrast, it is not known whether parental overevaluation of knowledge in comparison to youth self-reports consistently extends to perceptions of youth offending (Brummelman et al., 2015).

Often studies examining the influence of parenting dimensions on youth offending singularly rely upon youth self-reports (Lippold et al., 2014; Williams \& Steinberg, 2011). This single-reporter approach may result in bias when measuring various parenting dimensions. Evidence-based assessment practices suggest that using either a dyadic or multiple reporter approach has greater validity (Lippold et al., 2011). More recent research examining the influence of parenting dimensions on offending incorporates both parent and youth reports. Questions regarding the exact knowledge contribution garnered from each reporter and the relationship between the reporter perspectives remain. In assessing whether parent 
reports uniquely contribute to the prediction of delinquency, Bechtold and colleagues (2014) examine the predictive ability of mother reports and youth self-reports of impulsivity on arrest. Findings demonstrate mothers' ratings of their son's impulsivity predict arrest up to six years, whereas youth self-reports of impulsivity only reliably predict arrest for up to two and a half years. Bechtold et al. (2014, pp. 1909) describe the increased explanatory power as "incremental predictive validity" confirming the importance of parental (maternal) and youth reports.

Though most studies using multi-method reports of parenting behavior find overlap between youth and parent perceptions, significant and consistent discrepancies between the two groups exist (de los Reyes et al., 2010; Tein et al., 1994). Studies commonly find low to moderate agreement between youth and parent perceptions with mother-child reports of parental behavior demonstrating correlations of between .11 and .41 (Fogas \& Wolchick, 1986 as cited in Tein et al., 1994; Schwarz et al., 1985; Tein et al., 1994; Vieno et al., 2009). Augenstein and colleagues (2016) conclude that while youth and parent reports are correlated, they are not redundant. When incongruence between youth and parent reports exists, particularly where the parent perceives they have more knowledge than the child reports, or overestimates their knowledge, the likelihood of risky youth behavior is higher (Cottrell et al., 2003; de los Reyes et al., 2010). Also, when congruency among youth-parent dyads with low parental knowledge exists, or underestimates their knowledge, youth are more likely to be delinquent as compared to youth-parent dyads with congruent high parental knowledge (Crouter \& Head, 2002).

The limited studies that have explored both parent and youth perceptions of parental knowledge are not without their limitations for delinquency prevention efforts. For example, Cottrell and colleagues (2003) use cross sectional data from parents and youth in a rural community to understand congruency in perceptions of parenting. Their sample was comprised primarily of low income, Caucasian families with very few youths who engaged in any form of risky behavior. Here, risky behaviors considered included smoking cigarettes, consuming alcohol, or having sexual intercourse. For each category, less than 25\% reported engaging in such behavior. Important for future efforts is an increased focus on risk with demonstrably high risk of delinquency to determine parent youth discordance and the relationship with delinquency using panel data at minimum. Additionally, while de los Reyes and colleagues (2010) improve upon Cottrell et al., they limit their assessment of congruency to overestimation of knowledge and the Problem Behavior Frequency Scale as a measure of delinquency. While useful, this scale targets low level delinquency such as truancy, shoplifting, and vandalism rather that substantive offending behavior.

\section{The Current Study}

This study builds upon Bechtold et al.'s (2014) recommendation that researchers should examine the role of parent-child relationships and parenting style, as well as the degree to which parent and youth self-reports are predictive of future delinquency. We also improve upon the limitations of recent research 
in this area. We utilize parent and youth reports to assess multiple dimensions of parenting styles, congruency between the reporters, and the relative relationship of reporter discrepancies with the youth's self-reported offending behavior. For this study, we rely upon data from the Pathways to Desistance Study because it is uniquely suited to address these recommendations by its composition of high-risk offenders. We test the following directional and non-directional hypothesis based on the literature discussed.

$\mathrm{H}_{1}$ : Youth and parent reports of parenting measures will be positively correlated to a statistically significant degree representing a degree of congruency.

$\mathrm{H}_{2}$ : Parent reports of parenting measures will increase the explanatory power of the variance in offending variety scores above variance explained by youth reports alone.

$\mathrm{H}_{3}$ : Discordance between youth and parent perceptions of parenting measures will be significant related to youth offending variety scores.

\section{Method}

\section{Participants}

The current study draws upon youth who were participants in the Pathways to Desistance study during the baseline and collateral interviews portion of the study. The Pathways to Desistance research study is a multi-site, longitudinal study that followed serious juvenile offenders from adolescence to young adulthood between 2000 and 2010 (Mulvey \& Shubert, 2012). The Pathways to Desistance study began in 2000 with 645 adjudicated youth from juvenile and adult court systems in Maricopa County, Arizona and 700 adjudicated youth from Philadelphia County, Pennsylvania (Mulvey, 2000). ${ }^{2}$ Interviewers conducted baseline interviews with youth between November 2000 and January 2003. After researchers conducted initial baseline interviews, they conducted follow-up interviews every six months for the first three years, then annually for four years.

In addition to interviews with the delinquent youth, researchers conducted collateral interviews at baseline and at a one-year follow-up. The collateral interview respondent could be anyone known to the youth, but most collateral respondents at Time $1(82 \%)$ were parents who were primary caregivers (mostly women, 85\%). The non-parent (i.e., sibling, significant other, other relative, or other) collateral interviews were excluded. To be included in these analyses, youth and collateral interviewees must have both responded to all sections including the parenting measures section of the interview. Because of this criterion, our sample was restricted to 818 youth and parents. These youth were primarily males identifying as persons of color with an average age of 15.9 years old $(\mathrm{SD}=1.1)$.

\section{Measures}

\footnotetext{
${ }^{2}$ Average age was not significantly different by study site (mean $=15.9$, S.D. $=1.18$ for PA; mean = 15.9, S.D. $=$ 1.07 for AZ). A dummy variable reflecting study site was included in supplemental models to control for potential differences on relevant factors, and results were substantively similar to those presented here. Results available on request.
} 
Table 1 presents descriptive statistics for all measures including the youth and parent reports of parental knowledge and monitoring, youth reports of maternal warmth and maternal hostility, property and aggressive offending, and control variables.

\section{Parenting Measures}

Four parenting constructs are captured in this study: parental knowledge, parental monitoring, maternal warmth, and maternal hostility. All scales were pre-constructed in the Pathways to Desistance dataset, which were adapted from the Quality of Parental Relationships Inventory (Conger, Ge, Elder, Lorenz, \& Simons, 1994; see Appendix for full lists of items). Parental Knowledge and Parental Monitoring questions were asked about "the person who is primarily responsible for you." The Warmth and Hostility questions were asked separately for "mother/female caregiver" and "father/male caregiver." While most participants provide information about warmth and hostility relative to their "mother/female caregiver," there was a significant amount of missing data related to "father/male caregiver." For this reason and because women tend to be primary caregivers, analyses focus on warmth and hostility of the participants' female caregiver.

Parental Knowledge. Parental Knowledge is a five-item scale assessing how much parents know about the youth's whereabouts, friends, and activities (e.g., how much does your parent know about how you spend your free time). These items are asked in both the youth and parent (i.e., collateral) interviews. Each item is measured on a four-point scale ranging from $1=$ "doesn't know at all" to 4 = "knows everything." The pre-constructed scale represents the average of the items, and higher values on the scale indicate a greater degree of parental knowledge about the youth's activities.

Parental Monitoring. Parental Monitoring is a four-item scale assessing how much control parents exert over the youth's activities and behavior (e.g., how often do you have a set time to be home on weekend nights?). Each item is measured on a four-point scale from $1=$ never to $4=$ always. The preconstructed scale represents the average of the items with higher scale values indicating a higher level of parental monitoring.

Maternal Warmth. Maternal Warmth is a nine-item scale assessing the affective quality of the mother-youth relationship (e.g., how often does your mother tell you she loves you, let you know she really cares about you, etc.). The Quality of Parental Inventory (Conger, Ge, Elder, Lorenz \& Simons, 1994) was adapted for this construct (see Appendix A for individual items). Each item is measured on a four-point scale from $1=$ never to $4=$ always. The pre-constructed scale provides the average of the items with higher scale values indicate a more affectionate, warmer relationship.

Maternal Hostility. Maternal Hostility is a twelve-item scale adapted from Conger et al. (1994)'s Quality of Parental Inventory capturing level of hostility in the youth-mother relationship (e.g., how often does your mother get angry at you, throw things at you, etc.). Each item is measured on a four-point scale 
from $1=$ never to $4=$ always. The pre-constructed scale provides the average of the items with higher values indicate a more hostile mother-youth relationship.

\section{Offending Measures}

Two self-reported measures of offending are used in this study: a variety score of property offending and a variety score of aggressive offending. ${ }^{3}$ Respondents are asked in this study to indicate whether they had engaged in a series of 22 offending behaviors within the previous year. Eleven items reflect non-drug property or public order offenses (i.e., damaged or destroyed property, set a fire, broke into a building to steal something, shoplifted, bought/received/sold stolen property, used checks or credit cards illegally, stole a motor vehicle, drove drunk or high, paid for sex, broke into a car to steal something, joyriding). Eight items represent aggressive offenses (i.e., carjacked, shot and hit someone, shot at someone, robbery with a weapon, robbery with no weapon, participated in a gang fight, assaulted someone causing serious injury, carried a gun). Remaining items were masked for confidentiality and were not considered in this analysis. Questions for these measures were developed by the Pathways Study research team (Mulvey, 2013).

Dichotomous indicators for property offending and aggressive offending are respectively summed to create variety scores. The property offending variety score ranges from 0 to 10 types of property offending behaviors committed, with a mean of $2.12(\mathrm{SD}=2.26)$. The aggressive offending variety score ranges from 0 to 8 , with a mean of $1.30(\mathrm{SD}=1.71)$.

A subsequent, supplemental analysis extends the focus on analysis of parenting to explore causal effects of perceptions of parenting on youth offending. For this second stage analysis, both the property and aggressive offending variety scores are computed based on the one-year follow-up data. The same behavioral indicator as described above are used, but with a focus on offending behaviors that occurred between the baseline interview and the follow up interview. For these analyses, 776 youth respondents are included since they have complete baseline youth and collateral interview data and one-year follow-up data. The Time 2 property offending variety score ranges from 0 to 15 with a mean of $1.00(\mathrm{SD}=2.12)$. The Time 2 aggressive offending variety score ranges from 0 to 7 with a mean of $0.35(S D=0.90)$.

\section{Control Variables}

Several control variables are included in the multivariate models. Gender is coded as $0=$ female $(14.2 \% ; n=116)$ and $1=$ male $(85.8 \% ; n=702)$. A dichotomous measure captures race $(1=$ Person of Color; 74.4\%; $\mathrm{n}=609)$. Age at baseline is a continuous variable ranging from 14 to 18 , with an average of $15.89(\mathrm{SD}=1.12)$. Finally, multivariate analyses incorporate a scale measuring impulse control. The

\footnotetext{
${ }^{3}$ Variety scores are commonly used as an indicator of offending and are correlated with frequency scores, which are often used interchangeably. Monahan and Piquero (2009) note that the distributional properties, reliability, and predictive utility of variety scores are superior to frequency scores.
} 
Impulse Control scale is an average of eight items from the Weinberger Adjustment Inventory (Weinberger, 1997) that reflect the youth's level of impulse control (e.g., I say the first thing that pops into head without thinking about it). Respondents are asked to consider the previous six months and report how true each statement is of them (coded as $1=$ false to $5=$ true). The items are recoded and averaged so that higher values reflect more impulse control. Scale scores range from 1 to 5 with a mean of 2.97 (SD = 0.95).

\section{Analytical Approach}

This study uses a variety of analytical approaches to inform the stated hypothesis. First, descriptive and bivariate analyses examine both youth and parental perspectives to test the first hypothesis. Next, a set of sequential negative binomial regression models examining offense variety scores are conducted. First, youth reports of parental knowledge and monitoring are included, and then parent reports are added to determine whether the addition of these indicators significantly correlates with offending variety scores and improves explanatory power, net of control variables (Hypothesis 2). Finally, to test Hypothesis 3 , difference scores representing the degree to which youth have higher or lower values of the parenting measures in comparison to their parent's reports are calculated. Multivariate negative binomial regression models for the property and aggressive offending variety scores that include the same control variables are conducted. The final set of analyses to test hypothesis 3 combines these elements by using a personcentered approach, Latent Class Analysis (LCA), to uncover patterns of youth and parent reporting of knowledge and monitoring along with discrepancies. Recognizing these latent classes of parenting, multivariate models are estimated to predict the property and aggressive offending variety scores incorporating the same controls as used previously along with the categorical indicators of predicted class membership.

\section{Results}

\section{Youth Versus Parent Reports}

The first of inquiry informs hypothesis 1 and 2 with the questions: To what extent are youth and parent reports of parenting measures congruent? Are youth and parent reports independently related to youth offending? Table 2 presents correlations among the six parenting measures. While youth and parent reports are significantly correlated ( $r=.318, \mathrm{p}<.01$ for knowledge; $r=.306, \mathrm{p}<.01$ for monitoring), the overlap between the reporters is not overwhelming, with only $10.1 \%$ shared variance for parental knowledge and $9.4 \%$ for parental monitoring.

As shown in Table 3, in almost all cases parenting measures are significantly correlated with youth offending variety scores at the bivariate level. Parental knowledge, parental monitoring, and maternal warmth are negatively correlated to a statistically significant degree with property offending variety score for both youth and parent reporters. Maternal hostility is significantly and positively correlated with both 
property and aggressive offending variety scores. Maternal warmth is only significantly correlated with the aggressive offending variety score. While these results confirm congruency anticipated in hypothesis 1 , the extent of explained variance should result in a cautionary interpretation of this relationship.

Next to test hypothesis 2, we examine whether parent reports add to the explanatory power in understanding offending variety scores, beyond youth reports. As count variables with overdispersion, multivariate negative binomial models were estimated to predict both property and aggressive offending variety scores, a negative binomial regression model was used. Eq. (1) presents the negative binomial regression model (see Britt et al., 2017), which includes an individual-level error term that allows for unobserved heterogeneity. In this approach, the overdispersion of property and aggressive offending variety scores is modeled as a linear function of the mean such that " $k$ represents the count, $\lambda$ represents the mean, and $\theta$ represents the dispersion parameter" (Britt et al., 2017, p. 594).

$$
P(y=k)=\frac{\Gamma(\lambda / \theta+k)}{\Gamma(\lambda / \theta) \Gamma(k+1)}\left(\frac{1}{1+\theta}\right)^{\lambda / \theta}\left(\frac{\theta}{1+\theta}\right)^{k}
$$

The variance of the model expressed in Eq.1 is $\lambda(1+\theta)$, and with this form of the negative binomial regression model notes the expected value of the dependent variable (i.e., offending) as $\mathrm{E}(y)=\lambda$ $=\exp (\mathrm{X} B)$, which Britt et al. indicate is interpreted with the exponentiated coefficient measuring "the incident risk ratio (IRR) for a one unit change in the covariate."

Table 4 provides results from multivariate analyses of property and aggressive offending variety scores at baseline. For each dependent variable, the first model includes youth reports of parental knowledge and parental monitoring, along with maternal warmth and maternal hostility while controlling for gender, race, age, and level of impulse control. The second model adds the parent reports of parental knowledge and monitoring. In a negative binomial regression model for the property offending variety score, youth reports of higher levels of parental knowledge and parental monitoring are related to lower offending variety scores net of control variables. When parent reports are included in the model, coefficients for both youth report of parenting measures remain statistically significant, and the higher parent reports of parental knowledge results in a lower offending variety score to a statistically significant degree. A likelihood-ratio test indicates that the model including both youth and parent reports is a significantly better fit than the model with only youth reports $\left(\chi^{2}=7.09, \mathrm{p}<.05\right)$. Thus, youth and parent reports of parental knowledge appear to have independent, additive effects for understanding youth property offending confirming hypothesis 2 .

Results are similar in the negative binomial regression models predicting the self-reported aggressive offending variety score. In the youth report only model, higher levels of both parental knowledge and parental monitoring are significantly related to lower aggressive offending variety scores net of control variables. Interestingly, higher levels of maternal warmth and maternal hostility are 
significantly related to higher rates of aggressive offending variety scores. In the second model when parent reports are added, the relationship of youth reports with offending remains significant. The higher levels of parent reported parental knowledge is significantly related to lower levels of aggressive offending variety scores net of controls even further. The likelihood ratio test comparing the full and reduced models is marginally significant $\left(\chi^{2}=5.34, p=.069\right)$. Although the fit is only marginally improved, this finding does confirm hypothesis 2 .

\section{Differences in Youth-Parent Reports}

While the absolute levels of parenting measures appear to play a role in offending, it is possible that the key feature of parenting is the discrepancy or discordance between youth and parent perceptions of parenting behaviors. Following de Los Reyes et al. (2010) and Lippold et al. (2011) along with recommendations for current practice, standardized difference scores are calculated to reflect discrepancies in reporting. Youth and parent reports of parental knowledge and parental monitoring were first standardized, and then the parent score was subtracted from the youth score. The resulting difference score represent the degree to which youth have higher or lower values of the parenting measures in comparison to their parent's reports. Positive score indicates that youth report a higher degree of parental knowledge or parental monitoring as compared to their parent (i.e., youth overestimation of parenting). Negative scores indicate youth report lower levels compared to their parent (i.e., youth underestimation of parenting). It is important to note that this analytical approach is not intended to indicate the parent perception is the most objective perspective; instead, one of the two reports must serve as the comparison category. Here, we select the parent report as the base and compare youth reports as overestimated or underestimated in relation to the parent perception.

Table 5 presents descriptive statistics for both the average youth/parent scores and the difference scores and correlations with offending. Average levels of parental knowledge and parental monitoring are both significantly and negatively correlated with property and aggressive offending variety scores. Additionally, a greater overestimation of parenting of youth to parent reports (i.e., youth > parent) for parental knowledge and parental monitoring measures is significantly correlated with a lower property offending variety score $(\mathrm{r}=-.093, \mathrm{p}<.01$ for knowledge; $\mathrm{r}=-.061, \mathrm{p}<.05$ for monitoring $)$ and aggressive offending variety score ( $r=-.073, p<.01$ for knowledge; $r=-.101, p<.01$ for monitoring).

Table 6 presents multivariate negative binomial regression models for the property and aggressive offending variety scores that include the same control variables as described previously along with maternal warmth and maternal hostility. To reflect discrepancies in youth and parent reporting, two sets of variables are added. The difference scores are included to reflect the discrepancy between youth and parent reports. Additionally, the average of the youth and parent reports for both parental knowledge and parental monitoring are included to control for overall levels of parental knowledge and parental 
monitoring (see de Los Reyes et al., 2010). In both models, the average levels of parental knowledge and parental monitoring are significantly related to lower property and aggressive offending variety scores. Additionally, the difference score for parental knowledge (but not parental monitoring) significantly impacts the property offending variety score. Youth reporting higher levels of parental knowledge relative to parental reports is significantly associated with a lower property offending variety score. Conversely, the parental monitoring difference score (but not parental knowledge) is significant in the aggressive offending model. Youth reporting higher than parent reports (i.e., overestimating) of parental monitoring is significantly associated with lower aggressive offending variety scores. These findings confirm the nondirectional statement of hypothesis 3 that discordance between youth and parent perceptions of parenting measures will be significant related to youth offending variety scores.

\section{Latent Class Analysis of Reporting Behaviors}

The final set of analyses attempts to combine all these elements by using a person-centered approach, Latent Class Analysis (LCA), to uncover patterns of youth and parent reporting of knowledge and monitoring along with discrepancies. Following Lippold et al. (2014), each of the six parenting measures is dichotomized at the median. Like factor analysis which groups variables, LCA groups individuals by different response patterns to each of the six parenting measures. With six variables $(j)$ and two response categories for each $\left(r_{j}\right)$, there are 64 possible response patterns (i.e., $2^{6}=64$ ), and $y$ represents a specific response pattern. LCA assumes that the patterns of responses reflect an underlying latent variable with a certain number of mutually exclusive categories ( $c$; see Porcu \& Giambona, 2017; Sullivan et al., 2009). In Eq. (2), the LCA model predicts the probability of a particular response pattern as a function of two parameters, the probability of membership in each category of latent class $c\left(\gamma_{c}\right)$ and the probability of response $i$ to item $j$ conditional on class membership $\left(\rho_{\mathrm{i} \mid c}\right)$.

$p(\mathbf{Y}=y)=\sum_{c=1}^{C} \gamma_{c} \prod_{j=1}^{J} \prod_{r_{j}=1}^{R_{j}} \rho_{j, r_{j} \mid c}^{I\left(y_{j}=r_{j}\right)}$

We test models with between two and six latent classes. Analyses are conducted in MPlus7 (Muthen \& Muthen, 2012; see Table VII). Selection of the appropriate number of classes relies on several fit statistics. Ultimately, a four-class model is selected based on the highest entropy value produced (see Wang et al. 2017 for discussion on class selection based on entropy values).

The results from the four-class model (Figure 1) illustrate the differences between the four identified groups on the probability of having a score above the median. The first group is identified as "Youth > Parent" comprises about $13.3 \%$ of the sample. The group demonstrates high probabilities that youth reports are above the median, with somewhat lower probabilities for parent reports. They are characterized by high maternal warmth and low maternal hostility. The next group, "Youth < Parent," comprises $20.7 \%$ of the sample. In this group, parent reports of parental knowledge and parental monitoring are higher than youth reports, and the group has relatively low levels of maternal warmth and 
high levels of maternal hostility. The "Low Parental Involvement" group comprises more than half of the sample (53.5\%). This group demonstrates low scores on all the parenting measures, regardless of reporter, low levels of maternal warmth, but the highest levels of maternal hostility. Finally, the smallest group (12.5\% of the sample) can be characterized as "Knowledge-Focused." This group demonstrates higher levels of both youth and parent reports of parental knowledge and maternal warmth, with relatively lower levels of monitoring and the lowest level of maternal hostility.

Recognizing these latent classes of parenting, multivariate models are estimated to predict the property and aggressive offending variety scores incorporating the same controls as used previously along with the categorical indicators of predicted class membership (See Table 9). The "Youth > Parent" group is the excluded reference category. In both the property and aggressive offending models, the "Low Parental Involvement" group has significantly greater variety scores as compared to the "Youth > Parent" (i.e., the reference category). Additional post-hoc tests indicate that the "Low Parental Involvement" coefficients are also significantly greater than those for both the "Youth < Parent" and the "Knowledge Focused" groups. Thus, youth in the "Low Parental Involvement" group have the greatest level of selfreported offending. The "Youth > Parent" group has the lowest level of self-reported offending.

\section{Parenting and Time 2 Offending}

A final set of analyses considers parenting further and explores the potential relationship of youth versus parent reports of parenting on youth offending. With the previous cross-sectional analyses of parenting and offending, results indicated correlations between these various parenting measures; however, it is important to consider the possible relationships between parenting measures and subsequent youth offending. To begin an assessment of the potential causal role of the parenting measures identified above, multivariate models are estimated predicting Time 2 property and aggressive offending variety scores incorporating the same controls as used previously along with the categorical indicators of predicted class membership (See Table 10). ${ }^{4}$ Again, the "Youth > Parent" group is the excluded reference category. It is important to recognize that involvement in offending has reciprocal effects on parenting behaviors, possibly altering actual parental knowledge and parental monitoring. For example, with system-involved youth, parents may feel hopeless and abdicate their parental role, or may try to help their children by becoming more involved. For this exploratory analysis, we will initially consider a unilateral approach.

In both the property and aggressive offending models, the "Low Parental Involvement" group has significantly greater Time 2 variety scores as compared to the "Youth > Parent" group (i.e., the reference category). Thus, youth in the "Low Parental Involvement" group have higher levels of self-reported

\footnotetext{
${ }^{4}$ An additional model included a control for "time at risk." The coefficient for that variable did not significantly predict offending in either model. Conclusions were unchanged for all the key variables.
} 
offending. Additionally, coefficients for the "Youth < Parent" group are positive and significant in both models. In other words, youth who reported lower levels of parental knowledge and parental monitoring relative to parent reports are significantly more likely to engage in a variety of property and aggressive offending than those who reported higher levels of those parental measures.

\section{Discussion}

Nearly 40 years ago, researchers began to grapple with questions related to the influence of parenting on healthy psychosocial development of youth. Studies have refined assessment of this topic over the years with questions remaining as to the most effective modality of ascertaining reports of youth behavior and parenting dimensions. Researchers have determined the need for multiple reporters (i.e., parents and youth) to assess parenting style dimensions, with an added emphasis on assessing the congruency between these reports and the relative perceptions of the reporters. Prior studies have suggested that in addition to the parenting dimensions, the relative influence of reporter discrepancies may also affect the extent of the youth's self-reported delinquency. Data from the Pathways to Desistance study, a sample of high-risk incarcerated youth, enabled the exploration of these relationships in the current study. This high-risk sample ensured a sufficiently high likelihood of delinquent behavior was possible as compared to prior studies that have utilized community samples of non-system involved youth (Bechtold et al., 2014; Snyder \& Sickmund, 2006). A measure of self-reported offending was also used as studies have found this approach to be a more accurate measure of offending among youth than official records (Brame et al., 2012; Farrington et al., 2003; Maxfield et al., 2000).

The important analytical approaches used herein resulted in findings that further extend the existing knowledge on parenting dimensions and delinquency in important ways. First and foremost, findings indicate that parenting does matter in the level of youth offending, particularly the youth's perceptions of the parenting. Youth perceptions of parenting have the highest relative impact on offending. Parent reports also independently contribute significantly to the likelihood of youth offending, along with discrepancies in reporting between youth and parents.

Some distinctions in the relationship between parenting dimensions and offending by offense type exist. For example, parental knowledge plays the biggest role in the extent of youth involvement in property offending. Parental monitoring, especially the discrepancy between youth and parent reports of monitoring, plays a significant role in the prevalence of aggressive offending. It may be that aggression is a more impulsive behavior and thus more responsive to parental efforts of direct control as seen in the monitoring aspect of parenting.

Another important finding is that parenting matters for all youth including high-risk youth. Recall that the youth examined in this study were comprised of a high-risk population of incarcerated youth rather than a community sample, as is common in prior studies. Even for youth who were deeply 
embedded in offending and the criminal justice system, an opportunity for behavioral change and desistance remained as demonstrated by their responsiveness to positive parenting practices, especially in the extension of analyses to predict Time 2 offending. These findings reinforce the use of family-based prevention and treatment programs with serious juvenile offenders either while they reside in residential corrections facilities or as part of an aftercare planning process upon release.

Finally, it merits underscoring that both youth and parent perceptions of parenting matter. Although youth perceptions are a more robust predictor of offending, parent-reported knowledge uniquely contributes to the likelihood of property offending. In both community samples as determined in prior studies and with high-risk populations of youth as determined here, findings demonstrate the importance of measuring multiple reporters of parenting dimensions when studying the effects of parenting on delinquency as well as direction of reporting discrepancies between the youth and parent.

Important advances in the literature result from this study, but its limitations should be noted to contextualize these findings. Foremost, the analyses presented here rely on only two waves of data from the Pathways to Desistance study because sufficient collateral parent interviews were only available at those waves. It is likely that the nature of the parent-child relationship changes over time, and future research should extend these analyses over time to capture that variation. Related to our reliance on this study is the measures of key variables were predetermined by the study. We elected to keep the measures intact to maintain the integrity of these data. Still, as one reviewer noted some measures are limited. Specifically, parental monitoring items pertain to the imposition of time-limits on the youth's whereabouts which arguably overlaps with the measure of parental knowledge. Moreover, the parenting scale do not fully capture parental monitoring actions that may be available with current technology. We encourage researchers to consider new approaches to measuring these concepts in future studies.

Second, a limitation in survey research that may have influenced our findings is social desirability bias. This type of participant reporting bias is the tendency for individuals to alter their responses to align with their perceived societal expectations rather than to respond to questions directly and honestly. Although social desirability bias is more likely to occur when discussing taboo topics (Krumpal, 2011), youth can be especially sensitive to the need for social approval from the interviewer or be hesitant to report violent and non-violent behaviors (Davis, Thake, \& Vilhena, 2010; Moncher \& Miller, 1999; O'Donnell et al., 1999). Further, adult reporters may be defensive of their parenting skills as part of the collateral interviews associated with an effort focusing on high-risk youth (DiGiunta et al., 2020; Lange, Callinan \& Smith, 2019).

Third, our focus is on high-risk youth in this study. This is an advantage in extending existing literature by examining this unique group when community samples are typically the norm. It is important for researchers to determine whether these findings generalize to lower risk system involved youth and to 
youth who are not involved in the criminal justice system but may exhibit delinquent behavior. While not necessarily a limitation of the study itself, findings may not generalize in all cases. The use of a sample of high-risk youth may also account for the one counterintuitive result, that a greater degree of maternal warmth was associated with increased aggressive offending. Given that these youth were already involved in offending behavior, it is possible that higher levels of maternal warmth may be perceived as tacit approval or tolerance of the youth's delinquent behavior. While we were not able to disentangle this finding here, future research should consider the interplay of youth and parent relationship characteristics over the course of a delinquent trajectory.

Lastly, we were not able to include characteristics of the neighborhoods in which these families resided or give full consideration of reciprocal relationships. Researchers have suggested that family processes vary and "parental monitoring, especially supervision, may be more strongly related to problem behavior in neighborhoods that are unsafe" (Lippold et al., 2011, pp. 1187). Thus, the social context of family dynamics, specifically parenting behavior, may be dependent upon factors such as level of neighborhood disorder and vary by indicators such as closure and integration (e.g., how many neighbors would tell your parents, etc.). Reciprocal relationships may also exist such that higher rates and frequency of delinquency may result in declining parental warmth and monitoring over time (see for example Williams \& Steinberg, 2011). Accounting for reciprocal relationships between parenting and delinquency among youth of varying risk levels is an important next step in this area of research.

This paper aimed to advance knowledge on the role of parents in youth offending, and to understand the complexities associated with dimensions of both parenting and offending. Other factors not examined here likely contribute, mediate, or moderate these relationships as well. For example, while the composition of our sample reflected the general youth offender population, we suspect gendered effects of parenting on offending likely exist. Studies have found that in some families, parental warmth as well as discipline styles varying based on gender of the child (see for example Munoz-Suazo, NavarroMunoz, et al. (2020). We strongly encourage researchers to consider these factors in future research endeavors.

When taken as a whole, the findings presented in this study demonstrate the importance of parent-youth communication patterns, along with the need to have a clearer understanding of the transactional process within the dyad to improve perceptual congruency. In addition to improving youth outcomes, Bechtold and colleagues (2014, pp. 1904) remind us that for system involved youth, parental perceptions of youth behavior are critical to clinical and juvenile justice professionals. System actors such as probation officers often solicit parental reports on youths' behavior and characteristics before making treatment and sanction recommendations to the courts. Findings that underscore the relevance of parent reports of parental knowledge and monitoring of youth activities for the reduction of juvenile property 
offending supports this continued reliance on parents in this role. Future research should investigate the youth-parent transactional communication process to improve dyadic communication. Equipping parents and youth with skills and tools to improve communication is important to possible regulation of youth behavior that has forethought and planning (i.e., property offenses). In contrast, researchers should determine more effective interventions that aim to reduce offending that includes reactive or aggressive behaviors which may require a renewed focus on equipping the youth to improve their emotional reactivity. 


\section{References}

Baumrind, D. (1968). Authoritarian vs. authoritative parental control. Adolescence, 3(11), 255-272.

Bechtold, J., Cavanagh, C., Shulman, E. P., \& Cauffman, E. (2014). Does mother know best? Adolescent and mother reports of impulsivity and subsequent delinquency. Journal of Youth and Adolescence, 43(11), 1903-1913. https://doi.org/10.1007/s10964-013-0080-9

Bountress, K., Chassin, L., \& Lemery-Chalfant, K. (2017). Parent and peer influences on emerging adult substance use disorder: A genetically informed study. Development and Psychopathology, 29(1), 121-142. https://doi.org/10.1017/S095457941500125X

Brame, R., Turner, M. G., Paternoster, R., \& Bushway, S. D. (2012). Cumulative prevalence of arrest from ages 8 to 23 in a national sample. Pediatrics, 129(1), 21-27. https://doi.org/10.1542/peds.20103710

Britt, C. L., Rocque, M., \& Zimmerman, G. M. (2018). The analysis of bounded count data in criminology. Journal of Quantitative Criminology, 34, 591-607. https://doi.org/10.1007/s10940-017-9346-9

Brummelman, E., Thomaes, S., Nelemans, S. A., Orobio de Castro, B., \& Bushman, B. J. (2015). My child is God's gift to humanity: Development and validation of the Parental Overevaluation Scale (POS). Journal of Personality and Social Psychology, 104, 665679. https://doi.org/10.1037/pspp0000012

Chung, H. L., \& Steinberg, L. (2006). Relations between neighborhood factors, parenting behaviors, peer deviance, and delinquency among serious juvenile offenders. Developmental Psychology, 42, 319331. https://doi.org/10.1037/0012-1649.42.2.319

Cleveland, M. J., Feinberg, M. E., Osgood, D. W., \& Moody, J. (2012). Do peers' parents matter? A new link between positive parenting and adolescent substance use. Journal of Studies on Alcohol and Drugs, 73, 423-433. https://doi.org/10.15288/jsad.2012.73.423

Conger, R., Ge, X., Elder, G., Jr. Lorenz, F., \& Simons, R. (1994). Economic stress, coercive family process, and developmental problems of adolescents. Child Development, 65, 541-561. https://doi.org/10.2307/1131401

Cottrell, L., Li, X., Harris, C., D'Alessandri, D., Atkins, M., Richardson, B., \& Stanton, B. (2003). Parent and adolescent perceptions of parental monitoring and adolescent risk involvement. Parenting: Science and Practice, 3(3), 179-195.

https://doi.org/10.1207/S15327922PAR0303_01

Crouter, A. C., \& Head, M. R. (2002). Parental monitoring and knowledge of children. In M. H. Bornstein (Ed.), Handbook of parenting: Being and becoming a parent (pp. 461-483). Lawrence Erlbaum Associates Publishers.

Davidov, M., \& Grusec, J. E. (2006). Untangling the links of parental responsiveness to distress and warmth to child outcomes. Child Development, 77(1), 44-58. https://doi.org/10.1111/j.1467$\underline{8624.2006 .00855 . x}$

Davis, C. G., Thake, J., \& Vilhena, N. (2010). Social desirability biases in self-reported alcohol consumption and harms. Addictive Behaviors, 35(4), 302-311. https://doi.org/10.1016/j.addbeh.2009.11.001 
De Los Reyes, A., Goodman, K. L., Kliewer, W., \& Reid-Quiñones, K. (2010). The longitudinal consistency of mother-child reporting discrepancies of parental monitoring and their ability to predict child delinquent behaviors two years later. Journal of Youth and Adolescence, 39(12), 1417-1430. https://doi.org/10.1007/s10964-009-9496-7

Demo, D. H., Small, S. A., \& Savin-Williams, R. C. (1987). Family relations and the self-esteem of adolescents and their parents. Journal of Marriage and the Family, 49(4), 705715. https://doi.org/10.2307/351965

Di Giunta, L., Rothenberg, W. A., Lunetti, C., Lansford, J. E., Pastorelli, C., Eisenberg, N., Thartori, E., Basili, E., Favini, A., Yotanyamaneewong, S., Peña Alampay, L., Al-Hassan, S. M., Bacchini, D., Bornstein, M. H., Chang, L., Deater-Deckard, K., Dodge, K. A., Oburu, P., Skinner, A. T., . . Uribe Tirado, L. M. (2020). Longitudinal associations between mothers' and fathers' anger/irritability expressiveness, harsh parenting, and adolescents' socioemotional functioning in nine countries. Developmental Psychology, 56(3), 458-474. https://doi.org/10.1037/dev0000849

Dishion, T. J., \& McMahon, R. J. (1998). Parental monitoring and the prevention of child and adolescent problem behavior: a conceptual and empirical formulation. Clinical Child and Family Psychology Review, 1(1), 61-75. https://doi.org/10.1023/a:1021800432380

Farrington, D. P., Jolliffe, D., Hawkins, J. D., Catalano, R. F., Hill, K. G., \& Kosterman, R. (2003). Comparing delinquent careers in court records and self-reports. Criminology, 41, 933-958.

Gaylord, N. K., Kitzmann, K. M., \& Coleman, J. K. (2003). Parents' and children's perceptions of parental behavior: Associations with children's psychosocial adjustment in the classroom. Parenting: Science and Practice, 3(1), 23-47. https://doi.org/10.1207/S15327922PAR0301_02

Hoeve, M., Dubas, J. S., Eichelsheim, V. I., van der Laan, P. H., Smeenk, W., \& Gerris, J. R. M. (2009). The relationship between parenting and delinquency: A meta-analysis. Journal of Abnormal Child Psychology, 37, 749-775. https://doi.org/10.1007/s10802-009-9310-8

Johnson, W. L., Giordano, P. C., Manning, W. D., \& Longmore, M. A. (2011). Parent-child relations and offending during young adulthood. Journal of Youth and Adolescence,40(7), 786-799. https://doi.org/10.1007/s10964-010-9591-9

Krumpal, I. (2013). Determinants of social desirability bias in sensitive surveys: A literature review. Quality \& Quantity: International Journal of Methodology, 47(4), 20252047. https://doi.org/10.1007/s11135-011-9640-9

Lange, B., Callinan, L. S., \& Smith, M. V. (2019). Adverse childhood experiences and their relation to parenting stress and parenting practices. Community Mental Health Journal, 55(4), 651-662. https://doi.org/10.1007/s10597-018-0331-Z

Lippold, M. A., Greenberg, M. T., \& Collins, L. M. (2014). Youths' substance use and changes in parental knowledge-related behaviors during middle school: A person-oriented approach. Journal of Youth and Adolescence, 43(5), 729-744. https://doi.org/10.1007/s10964-013-0010-X

Lippold, M. A., Greenberg, M. T., \& Feinberg, M. E. (2011). A dyadic approach to understanding the relationship of maternal knowledge of youths' activities to youths' problem behavior among rural 
adolescents. Journal of Youth and Adolescence, 40(9), 11781191. https://doi.org/10.1007/s10964-010-9595-5

Luyckx, K., Tildesley, E. A., Soenens, B., Andrews, J. A., Hampson, S. E., Peterson, M., \& Duriez, B. (2011). Parenting and trajectories of children's maladaptive behaviors: A 12-year prospective community study. Journal of Clinical Child and Adolescent Psychology,40(3), 468-478. https://doi.org/10.1080/15374416.2011.563470

Maccoby, E. E., \& Martin, J. A. (1983). Socialization in the context of the family: Parent-child interactions. In P. H. Mussen (Ed.), Handbook of Child Psychology: Socialization, Personality and Social Development [vol. IV(p. 1-101)]. New York: Wiley.

Maxfield, M. G., Weiler, B. L., \& Widom, C. S. (2000). Comparing self-reports and official records of arrests. Journal of Quantitative Criminology, 16(1), 87110.https://doi.org/10.1023/A:1007577512038

Moncher, F. J., \& Miller, G. E. (1999). Nondelinquent youths' stealing behavior and their perceptions of parents, school, and peers. Adolescence, 34(135), 577-591.

Mulvey, E. P. (2013). Research on Pathways to Desistance [Maricopa County, AZ and Philadelphia County, PA]: Subject Measures, 2000-2010. ICPSR29961-v2. Ann Arbor, MI: Inter-university Consortium for Political and Social Research [distributor], 2013-01-07. http://doi.org/10.3886/ICPSR29961.v2

Mulvey, E. P. (2013). Research on Pathways to Desistance [Maricopa County, AZ and Philadelphia County, PA]: Collateral Measures, 2000-2004. ICPSR32881-v1. Ann Arbor, MI: Inter-university Consortium for Political and Social Research [distributor], 2013-01-07. http://doi.org/10.3886/ICPSR32881.v1

Mulvey, E. P., \& Schubert, C. A. (2012). Some initial findings and policy implications of the Pathways to Desistance Study. Victims \& Offenders, 7(4), https://doi.org/10.1080/15564886.2012.713903

Munoz-Suazo, M.D., Navarro-Munoz, J., Diaz-Roman, A., Coronilla-Garcia, M., Porcel-Galvez, A., \& GilGarcia, E. (2020). Parenting practices among parents of children with attentiondeficit/hyperactivity disorder: Gender-related differences. Journal of Clinical Psychology, 239-245. https://doi.org/10.1002/jclp.22873

Muthen, L. K., \& Muthen, B. O. (2012). Mplus: Statistical Analysis with Latent Variables. User's Guide. Los Angeles, CA: Muthen and Muthen.

O'Donnell, L., Stueve, A., San Doval, A., Duran, R., Atnafou, R., Haber, D., Johnson, N., Murray, H., Grant, U., Juhn, G., Tang, J., Bass, J., \& Piessens, P. (1999). Violence prevention and young adolescents' participation in community youth service. The Journal of Adolescent Health, 24(1), 28-37. https://doi.org/10.1016/s1054-139x(98)00069-x

Ohannessian, C. M., Laird, R., \& De Los Reyes, A. (2016). Discrepancies in adolescents' and mothers' perceptions of the family and mothers' psychological symptomatology. Journal of Youth and Adolescence, 45(10), 2011-2021. https://doi.org/10.1007/s10964-016-0477-3 
Perez-Gramaje, A. F., Garcia, O. F., Reyes, M., Serra, E., \& Garcia, F. (2020). Parenting styles and aggressive adolescents: Relationships with self-esteem and personal maladjustment. The European Journal of Psychology Applied to Legal Context, 12(1), 110. https://doi.org/10.5093/ejpalc2020a1

Porcu, M., \& Giambona, F. (2017). Introduction to latent class analysis with applications. Journal of Early Adolescence, 37, 129-158. https://doi.org/10.1177/0272431616648452

Ragan, D. T., Osgood, D. W., \& Feinberg, M. E. (2014). Friends as a bridge to parental influence: Implications for adolescent alcohol use. Social Forces, 92(3), 1061-1085. https://doi.org/10.1093/sf/sot117

Schwarz, J. C., Barton-Henry, M. L., \& Pruzinsky, T. (1985). Assessing child-rearing behaviors: a comparison of ratings made by mother, father, child, and sibling on the CRPBI. Child Development, 56(2), 462-479.

Simons, R. L., Simons, L. G., Burt, C. H., Brody, G. H., \& Cutrona, C. (2005). Collective efficacy, authoritative parenting and delinquency: A longitudinal test of a model integrating community and family-level processes. Criminology, 43(4), 989-1029. https://doi.org/10.1111/j.17459125.2005.00031.x

Snyder, H. N., \& Sickmund, M. (2006). Juvenile Offenders and Victims: 2006 National Report. Washington, DC: US Department of Justice, Office of Justice Programs, Office of Juvenile Justice and Delinquency Prevention.

Steinberg, L. (2001). We know some things: Adolescent-parent relationships in retrospect and prospect. Journal of Research on Adolescence, 11, 1-20. https://doi.org/10.1111/1532-7795.00001

Steinberg, L., Blatt-Eisengart, I., \& Cauffman, E. (2006). Patterns of competence and adjustment among adolescents from authoritative, authoritarian, indulgent, and neglectful homes: A replication in a sample of serious juvenile offenders. Journal of Research on Adolescence, 16, 47-58. https://doi.org/10.1111/j.1532-7795.2006.00119.x

Steinberg, L., Lamborn, S. D., Dornbusch, S. M., \& Darling, N. (1992). Impact of parenting practices on adolescent achievement: Authoritative parenting, school involvement, and encouragement to succeed. Child Development, 63, 1266-1281. https://doi.org/10.2307/1131532

Steinberg, L., Mounts, N. S., Lamborn, S. D., \& Dornbusch, S. M. (1991). Authoritative parenting and adolescent adjustment across varied ecological niches. Journal of Research on Adolescence, 1, 1936.

Sullivan, C. J., McGloin, J.M., Ray, J.V., \& Caudy, M.S. (2009). Detecting specialization in offending: Comparing analytic approaches. Journal of Quantitative Criminology, 25, 419-441. https://doi.org/OI 10.1007/s10940-009-9074-X

Tein, J.-Y., Roosa, M. W., \& Michaels, M. (1994). Agreement between parent and child reports on parental behaviors. Journal of Marriage and the Family, 56(2), 341-355. https://doi.org/10.2307/353104

Vieno, A., Nation, M., Pastore, M., \& Santinello, M. (2009). Parenting and antisocial behavior: a model of the relationship between adolescent self-disclosure, parental closeness, parental control, and 
adolescent antisocial behavior. Developmental Psychology,45(6), 1509-1519. https://doi.org/10.1037/a0016929

Wang, M. C., Deng, Q., Bi, X., Ye, H., \& Yang, W. (2017). Performance of the entropy as an index of classification accuracy in latent profile analysis: A Monte Carlo simulation study. Acta Psychologica Sinica, 49(11), 1473-1482. https://doi.org/10.3724/SP.J.1041.2017.01473

Weinberger, D. A. (1997). Distress and self-restraint as measures of adjustment across the life span: Confirmatory factor analyses in clinical and nonclinical samples. Psychological Assessment, 9(2), 132-135. https://doi.org/10.1037/1040-3590.9.2.132

Wenger, A., \& Fowler, B.J. (2008). Positive illusions in parenting: Every child is above average. Journal of Applied Social Psychology, 38, 611-634. https://doi.org/10.1111/j.1559-1816.2007.00319.x

White, R., Liu, Y., Gonzales, N. A., Knight, G. P., \& Tein, J. Y. (2016). Neighborhood Qualification of the Association Between Parenting and Problem Behavior Trajectories Among Mexican-Origin Father-Adolescent Dyads. Journal of Research on Adolescence, 26(4), 927-946. https://doi.org/10.1111/jora.12245

Williams, L. R., \& Steinberg, L. (2011). Reciprocal relations between parenting and adjustment in a sample of juvenile offenders. Child Development, 82(2), 633-645. https://doi.org/10.1111/j.1467$\underline{8624.2010 .01523 . \mathrm{X}}$ 
Table 1: Descriptive Statistics for Parenting, Offending, and Control Variables

\begin{tabular}{|c|c|c|c|c|c|}
\hline Variables & Percent & $M(\mathrm{SD})$ & Skewness & Kurtosis & Range \\
\hline Parental Knowledge (Youth) & & $2.78(0.78)$ & -0.183 & -0.768 & $1-4$ \\
\hline Parental Knowledge (Parent) & & $2.75(0.75)$ & -0.293 & -0.459 & $1-4$ \\
\hline Parental Monitoring (Youth) & & $2.84(0.85)$ & -0.284 & -0.976 & $1-4$ \\
\hline Parental Monitoring (Parent) & & $3.17(0.76)$ & -0.589 & -0.593 & $1-4$ \\
\hline Maternal Warmth (Youth) & & $3.19(0.69)$ & -0.705 & -0.361 & $1-4$ \\
\hline Maternal Hostility (Youth) & & $1.62(0.45)$ & 1.381 & 2.259 & $1-3.75$ \\
\hline $\begin{array}{l}\text { Property Offending Variety Score } \\
\text { (Past Year) }\end{array}$ & & $2.12(2.26)$ & 1.146 & 0.632 & $0-10$ \\
\hline Aggressive Offense (Past Year) & $54.4 \%$ & $1.30(1.71)$ & 1.610 & 2.396 & $0-8$ \\
\hline Male & $85.8 \%$ & & & & \\
\hline Person of Color & $74.4 \%$ & & & & \\
\hline Age at Baseline & & $15.89(1.12)$ & -0.183 & -0.862 & $14-18$ \\
\hline Impulse Control & & $2.97(0.95)$ & 0.101 & -0.671 & $1-5$ \\
\hline
\end{tabular}


Table 2: Correlations between Youth and Parent Perceptions and Behavior

\begin{tabular}{lllllll}
\hline Variables & $(1)$ & $(2)$ & $(3)$ & $(4)$ & $(5)$ & $(6)$ \\
\hline (1) Youth - Knowledge & --- & & & & \\
(2) Youth - Monitoring & $.328^{* *}$ & --- & & & \\
(3) Parent - Knowledge & $.318^{* *}$ & $.156^{* *}$ & --- & & \\
(4) Parent - Monitoring & $.205^{* *}$ & $.306^{* *}$ & $.451^{* *}$ & --- & \\
(5) Youth - Maternal Warmth & $.254^{* *}$ & $.142^{* *}$ & .029 & .045 & --- \\
(6) Youth - Maternal Hostility & $-.214^{* *}$ & $-.104^{* *}$ & $-.122^{* *}$ & $-.073^{*}$ & $-.417^{* *}$ & --- \\
\hline
\end{tabular}

${ }^{*} \mathrm{p}<.05 ;{ }^{* *} \mathrm{p}<.01$. 
Table 3: Correlations between Youth and Parent Perceptions and Youth Offending Behavior

\begin{tabular}{|c|c|c|c|}
\hline Variables & $\begin{array}{l}\text { Property Offending Variety } \\
\text { Score }\end{array}$ & $\begin{array}{l}\text { Aggressive } \\
\text { Variety Score }\end{array}$ & Offending \\
\hline Youth - Knowledge & $-.284^{* *}$ & $-.254^{* *}$ & \\
\hline Youth - Monitoring & $-.181^{* *}$ & $-.213^{* *}$ & \\
\hline Parent - Knowledge & $-.176^{* *}$ & $-.169^{* *}$ & \\
\hline Parent - Monitoring & $-.109^{* *}$ & $-.094^{* *}$ & \\
\hline Youth - Maternal Warmth & $-.096^{* *}$ & -.001 & \\
\hline Youth - Maternal Hostility & $.179^{* *}$ & $.185^{* *}$ & \\
\hline
\end{tabular}


Table 4: Sequential Negative Binomial Regression Models Predicting Offending with Youth and Parent Reports of Parenting

\begin{tabular}{|c|c|c|c|c|c|c|c|c|}
\hline \multirow[b]{2}{*}{ Variables } & \multicolumn{4}{|c|}{ Property Offending Variety Score } & \multicolumn{4}{|c|}{ Aggressive Offending Variety Score } \\
\hline & $\begin{array}{l}\text { b } \\
\text { (s.e.) }\end{array}$ & IRR & $\begin{array}{l}\text { b } \\
\text { (s.e.) }\end{array}$ & IRR & $\begin{array}{l}\text { b } \\
\text { (s.e.) }\end{array}$ & IRR & $\begin{array}{l}\text { b } \\
\text { (s.e.) }\end{array}$ & IRR \\
\hline Constant & $\begin{array}{l}2.780 \\
(0.663)\end{array}$ & $16.122^{* *}$ & $\begin{array}{l}3.207 \\
(0.679)\end{array}$ & $24.715^{* *}$ & $\begin{array}{l}0.368 \\
(0.785)\end{array}$ & 1.445 & $\begin{array}{l}0.776 \\
(0.806)\end{array}$ & 2.173 \\
\hline Male & $\begin{array}{l}0.275 \\
(0.112)\end{array}$ & $1.317^{* *}$ & $\begin{array}{l}0.280 \\
(0.111)\end{array}$ & $1.323^{* *}$ & $\begin{array}{l}0.782 \\
(0.158)\end{array}$ & $2.185^{* *}$ & $\begin{array}{l}0.776 \\
(0.157)\end{array}$ & $2.172^{* *}$ \\
\hline Non-White & $\begin{array}{l}-0.131 \\
(0.083)\end{array}$ & 0.877 & $\begin{array}{l}-0.138 \\
(0.083)\end{array}$ & $0.871^{*}$ & $\begin{array}{l}0.322 \\
(0.108)\end{array}$ & $1.380^{* *}$ & $\begin{array}{l}0.318 \\
(0.107)\end{array}$ & $1.374^{* *}$ \\
\hline Age at Baseline & $\begin{array}{l}-0.038 \\
(0.034)\end{array}$ & 0.963 & $\begin{array}{l}-0.041 \\
(0.034)\end{array}$ & 0.960 & $\begin{array}{l}-0.023 \\
(0.041)\end{array}$ & 0.977 & $\begin{array}{l}-0.028 \\
(0.041)\end{array}$ & 0.972 \\
\hline Impulse Control & $\begin{array}{l}-0.334 \\
(0.041)\end{array}$ & $0.716^{* *}$ & $\begin{array}{l}-0.336 \\
(0.041)\end{array}$ & $0.715^{* *}$ & $\begin{array}{l}-0.321 \\
(0.049)\end{array}$ & $0.725^{* *}$ & $\begin{array}{l}-0.319 \\
(0.049)\end{array}$ & $0.727^{* *}$ \\
\hline Maternal Warmth & $\begin{array}{l}0.053 \\
(0.059)\end{array}$ & 1.054 & $\begin{array}{l}0.039 \\
(0.058)\end{array}$ & 1.039 & $\begin{array}{l}0.238 \\
(0.072)\end{array}$ & $1.269^{* *}$ & $\begin{array}{l}0.225 \\
(0.072)\end{array}$ & $1.252^{* *}$ \\
\hline Maternal Hostility & $\begin{array}{l}0.173 \\
(0.089)\end{array}$ & $1.189^{*}$ & $\begin{array}{l}0.152 \\
(0.089)\end{array}$ & $1.165^{*}$ & $\begin{array}{l}0.439 \\
(0.107)\end{array}$ & $0.551^{* *}$ & $\begin{array}{l}0.420 \\
(0.107)\end{array}$ & $1.523^{* *}$ \\
\hline \multicolumn{9}{|l|}{ Youth Reports } \\
\hline Parental Knowledge & $\begin{array}{l}-0.285 \\
(0.050)\end{array}$ & $0.752^{* *}$ & $\begin{array}{l}-0.249 \\
(0.051)\end{array}$ & $0.779^{* *}$ & $\begin{array}{l}-0.295 \\
(0.060)\end{array}$ & $0.744^{* *}$ & $\begin{array}{l}-0.256 \\
(0.062)\end{array}$ & $0.774^{* *}$ \\
\hline Parental Monitoring & $\begin{array}{l}-0.121 \\
(0.046)\end{array}$ & $0.886^{* *}$ & $\begin{array}{l}-0.111 \\
(0.048)\end{array}$ & $0.895^{* *}$ & $\begin{array}{l}-0.184 \\
(0.056)\end{array}$ & $0.832^{* *}$ & $\begin{array}{l}-0.187 \\
(0.058)\end{array}$ & $0.830^{* *}$ \\
\hline \multicolumn{9}{|l|}{ Parent Reports } \\
\hline Parental Knowledge & --- & --- & $\begin{array}{l}-0.108 \\
(0.054)\end{array}$ & $0.898^{*}$ & --- & --- & $\begin{array}{l}-0.143 \\
(0.066)\end{array}$ & $0.867^{*}$ \\
\hline Parental Monitoring & --- & --- & $\begin{array}{l}-0.043 \\
(0.053)\end{array}$ & 0.958 & --- & --- & $\begin{array}{l}0.011 \\
(0.065)\end{array}$ & 1.011 \\
\hline Pseudo-r2 & .186 & & .193 & & .196 & & .202 & \\
\hline $\begin{array}{l}\chi^{2} \text { Likelihood ratio test } \\
\text { model }\end{array}$ & ll vs. red & & $7.09^{*}$ & & & & $5.34^{\mathrm{a}}$ & \\
\hline
\end{tabular}


Table 5: Correlations between Knowledge and Monitoring Average and Differences Scores and Youth Offending Behavior

\begin{tabular}{|c|c|c|c|c|}
\hline Variables & $M(S D)$ & Range & $\begin{array}{l}\text { Property } \\
\text { Offending Variety } \\
\text { Score }\end{array}$ & $\begin{array}{l}\text { Aggressive } \\
\text { Offending Variety } \\
\text { Score }\end{array}$ \\
\hline \multicolumn{5}{|c|}{ Average Scores (Youth/Parent) } \\
\hline Parental Knowledge & $2.77(0.62)$ & $1.10-4.00$ & $-.285^{* *}$ & $-.261^{* *}$ \\
\hline Parental Monitoring & $3.01(0.65)$ & $1.13-4.00$ & $-.182^{* *}$ & $-.194^{* *}$ \\
\hline \multicolumn{5}{|c|}{ Difference Scores (Youth - Parent) } \\
\hline Parental Knowledge & $0.00(1.17)$ & $-3.94-3.89$ & $-.093^{* *}$ & $-.073^{* *}$ \\
\hline Parental Monitoring & $0.00(1.18)$ & $-3.26-4.21$ & $-.061^{*}$ & $-.101^{* *}$ \\
\hline
\end{tabular}


Table 6: Negative Binomial Regression Models Predicting Offending with Differences between Youth and Parent Reports

\begin{tabular}{|c|c|c|c|c|}
\hline \multirow{4}{*}{ Variables } & \multicolumn{2}{|c|}{ Property Offending } & \multirow{2}{*}{$\begin{array}{l}\text { Aggressive } \\
\text { Score }\end{array}$} & \multirow[t]{2}{*}{ Offending Variety } \\
\hline & Variety & & & \\
\hline & $\mathrm{b}$ & IRR & $\mathrm{b}$ & IRR \\
\hline & (s.e.) & & (s.e.) & \\
\hline \multirow[t]{2}{*}{ Constant } & 3.236 & $25.436^{* *}$ & 0.846 & 2.332 \\
\hline & $(0.682)$ & & $(0.810)$ & \\
\hline \multirow[t]{2}{*}{ Male } & 0.280 & $1.323^{* *}$ & 0.776 & $2.172^{* *}$ \\
\hline & $(0.111)$ & & $(0.157)$ & \\
\hline \multirow[t]{2}{*}{ Non-White } & -0.138 & $0.871^{*}$ & 0.318 & $1.374^{* *}$ \\
\hline & $(0.083)$ & & $(0.107)$ & \\
\hline \multirow[t]{2}{*}{ Age at Baseline } & -0.041 & 0.960 & -0.028 & 0.972 \\
\hline & $(0.034)$ & & $(0.041)$ & \\
\hline \multirow[t]{2}{*}{ Impulse Control } & -0.336 & $0.715^{* *}$ & -0.319 & $0.727^{* *}$ \\
\hline & $(0.041)$ & & $(0.049)$ & \\
\hline \multirow[t]{2}{*}{ Maternal Warmth } & 0.039 & 1.039 & 0.225 & $1.252^{* *}$ \\
\hline & $(0.058)$ & & $(0.072)$ & \\
\hline \multirow[t]{2}{*}{ Maternal Hostility } & 0.152 & $1.165^{*}$ & 0.420 & $1.523^{* *}$ \\
\hline & $(0.089)$ & & $(0.107)$ & \\
\hline \multicolumn{5}{|l|}{ Average of Youth/Parent } \\
\hline \multirow[t]{2}{*}{ Parental Knowledge } & -0.360 & $0.697^{* *}$ & -0.402 & $0.669^{* *}$ \\
\hline & $(0.065)$ & & $(0.079)$ & \\
\hline \multirow[t]{2}{*}{ Parental Monitoring } & -0.157 & $0.855^{* *}$ & -0.187 & $0.829^{* *}$ \\
\hline & $(0.062)$ & & $(0.075)$ & \\
\hline \multicolumn{5}{|c|}{ Differences Scores (Youth - Parent) } \\
\hline \multirow[t]{2}{*}{ Parental Knowledge } & -0.054 & $0.947^{*}$ & -0.043 & 0.958 \\
\hline & $(0.032)$ & & $(0.039)$ & \\
\hline \multirow[t]{2}{*}{ Parental Monitoring } & -0.027 & 0.973 & -0.079 & $0.924^{*}$ \\
\hline & $(0.032)$ & & $(0.039)$ & \\
\hline Pseudo-r2 & .193 & & .202 & \\
\hline
\end{tabular}

${ }^{*} \mathrm{p}<.05 ;{ }^{* *} \mathrm{p}<.01$, one-tailed. 
Table 7: Latent Class Analysis Fit Statistics for 6 Dichotomous Indicators above Median $(n=818)$

\begin{tabular}{|c|c|c|c|c|}
\hline Class & $\mathrm{BIC}$ & LMR & BLR & Entropy \\
\hline 2 & 6569.394 & $255.157^{\star *}$ & $260.591^{* *}$ & .554 \\
\hline 3 & 6550.511 & $64.458^{* *}$ & $65.831^{* *}$ & .640 \\
\hline 4 & 6575.070 & 21.922 & $22.389^{* *}$ & .681 \\
\hline 5 & 6604.023 & 17.620 & $17.996^{*}$ & .578 \\
\hline 6 & 6643.690 & 7.148 & 7.281 & .619 \\
\hline
\end{tabular}


Table 8: Negative Binomial Regression Models Predicting Offending with Predicted Parenting Latent Classes

\begin{tabular}{|c|c|c|c|c|}
\hline \multirow{4}{*}{ Variables } & \multicolumn{2}{|c|}{ Property Offending } & \multirow{2}{*}{\multicolumn{2}{|c|}{$\begin{array}{l}\text { Aggressive Offending Variety } \\
\text { Score }\end{array}$}} \\
\hline & Variety & & & \\
\hline & $\mathrm{b}$ & IRR & $\mathrm{b}$ & IRR \\
\hline & (s.e.) & & (s.e.) & \\
\hline \multirow[t]{2}{*}{ Constant } & 1.401 & $4.058^{* *}$ & -0.535 & 0.586 \\
\hline & $(0.550)$ & & $(0.671)$ & \\
\hline \multirow[t]{2}{*}{ Male } & 0.311 & $1.364^{* *}$ & 0.813 & $2.254^{* *}$ \\
\hline & $(0.111)$ & & $(0.157)$ & \\
\hline \multirow[t]{2}{*}{ Non-White } & -0.084 & 0.919 & 0.417 & $1.518^{* *}$ \\
\hline & $(0.083)$ & & $(0.109)$ & \\
\hline \multirow[t]{2}{*}{ Age at Baseline } & -0.007 & 0.994 & 0.026 & 1.027 \\
\hline & $(0.033)$ & & $(0.040)$ & \\
\hline \multirow[t]{2}{*}{ Impulse Control } & -0.384 & $0.681^{* *}$ & -0.392 & $0.676^{* *}$ \\
\hline & $(0.040)$ & & $(0.050)$ & \\
\hline \multicolumn{5}{|l|}{ Predicted Parenting Latent Class ${ }^{\mathrm{a}}$} \\
\hline \multirow[t]{2}{*}{ Youth $<$ Parent } & 0.047 & 1.048 & 0.211 & 1.235 \\
\hline & $(0.138)$ & & $(0.175)$ & \\
\hline \multirow[t]{2}{*}{ Low Parental Involvement } & 0.487 & $1.627^{* * b}$ & 0.578 & $1.782^{* * b}$ \\
\hline & $(0.120)$ & & $(0.152)$ & \\
\hline \multirow[t]{2}{*}{ Knowledge Focused } & 0.161 & 1.175 & 0.298 & 1.347 \\
\hline & $(0.155)$ & & $(0.192)$ & \\
\hline Pseudo-r2 & .159 & & .158 & \\
\hline
\end{tabular}

${ }^{*} \mathrm{p}<.05 ;{ }^{* *} \mathrm{p}<.01$, one-tailed

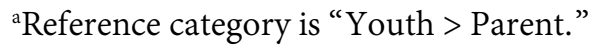

bA post-hoc test found that the coefficient for "Low Parental Involvement" is significantly different from "Youth Under-Estimators" and "Knowledge Focused" groups. 
Table 9: Negative Binomial Regression Models Predicting Time 2 Offending with Predicted Parenting Latent Classes

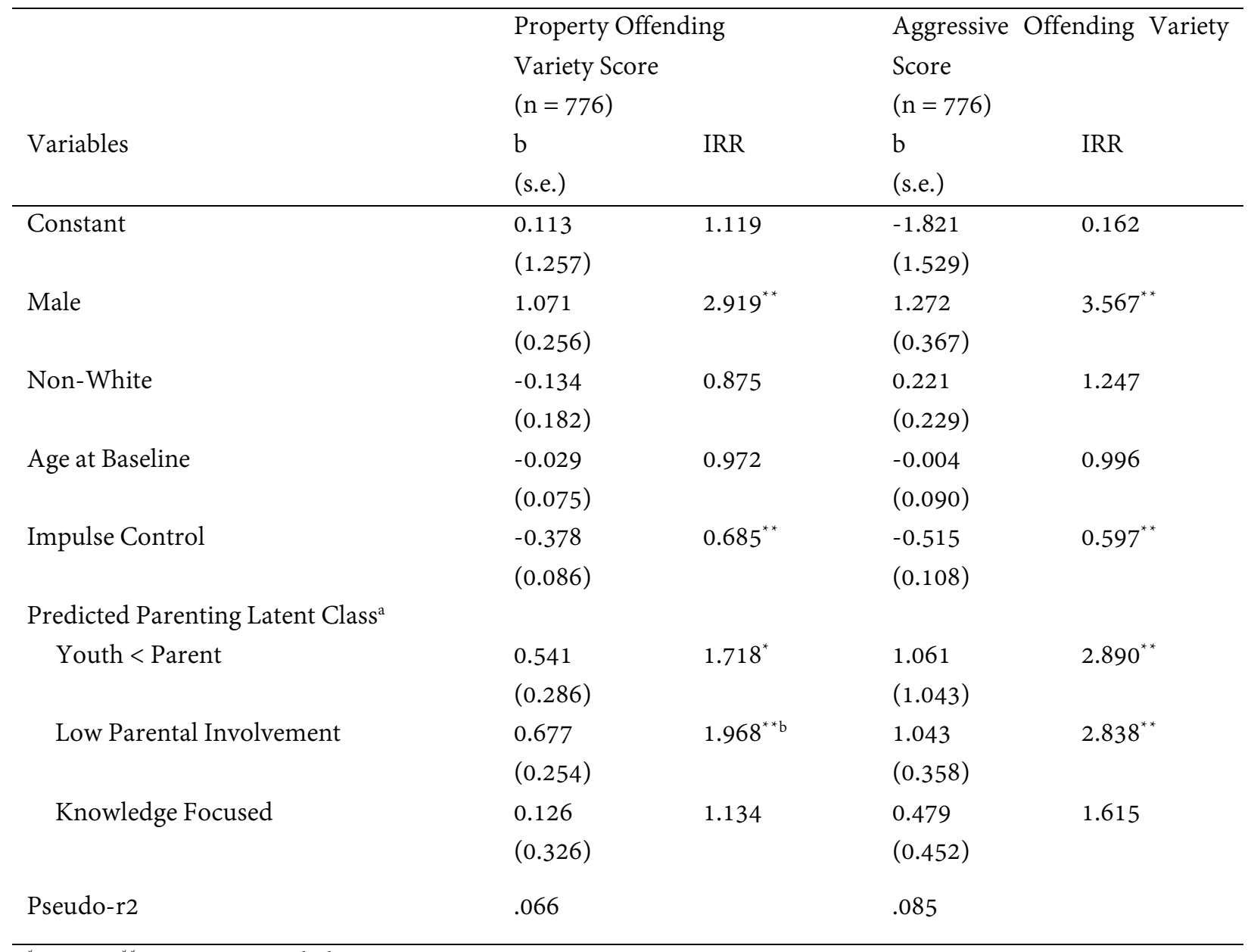

${ }^{*} \mathrm{p}<.05 ;{ }^{* *} \mathrm{p}<.01$, one-tailed

aReference category is "Youth $>$ Parent."

${ }^{b} \mathrm{~A}$ post-hoc test found that the coefficient for "Low Parental Involvement" is significantly different from the "Knowledge Focused" group. 
Figure 1: Predicted Latent Class Groups

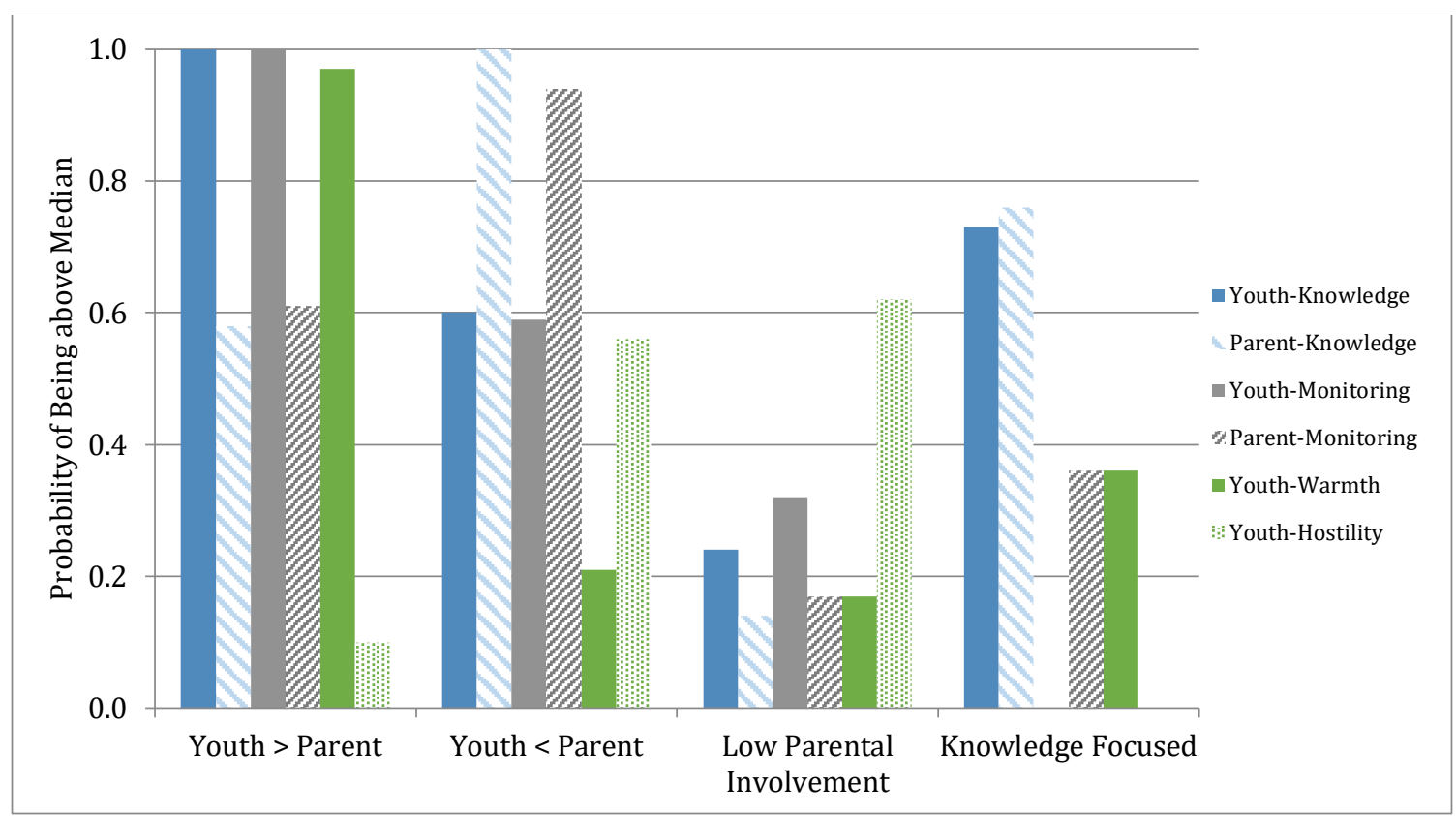


Parental Knowledge - asked about "the person primarily responsible for you"

- How much do they know about who you spend your time with?

- How much do they know about how you spend your free time?

- How much do they know about how you spend your money?

- How much do they know about where you go right after school/work?

- How much do they know about where you go at night?

Parental Monitoring - asked about "the person primarily responsible for you"

- How often do you have a set time to be home on school/work nights?

- How often do you have a set time to be home on weekend nights?

- How often do they know what time you will be home when you have gone out?

- How often do you leave a note/call about where you are going?

Maternal Warmth (alpha = .92) - asked about "mother/female guardian"

- How often does your mom help you do something important?

- How often does your mom let you know she cares?

- How often has your mom listened to your point of view?

- How often does your mom act supportive toward you?

- How often does your mom act loving toward you?

- How often does your mom have a good laugh with you?

- How often does your mom let you know she appreciates you/your ideas?

- How often does your mom say she loves you?

- How often does your mom understand the way you feel?

Maternal Hostility (alpha $=.85)$ - asked about "mother/female guardian"

- How often does your mom get angry with you?

- How often has your mom gotten so made she broke/threw things?

- How often does your mom shout because she was mad at you?

- How often does your mom threaten to hurt you physically?

- How often does your mom criticize your ideas?

- How often does your mom push/grab/hit/shove you?

- How often does your mom argue with you when you disagreed?

- How often does your mom slap or hit you with her hands?

- How often does your mom strike you with an object?

- How often does your mom boss you around?

- How often does your mom throw things at you?

- How often does your mom insult or swear at you? 